\title{
https://doi.org/10.30853/filnauki.2019.9.53
}

\section{Строкан Елена Владимировна}

МЕТАФОРИЧЕСКАЯ РЕПРЕЗЕНТАЦИЯ БРИТАНСКОЙ МОНАРХИИ: АКСИОЛОГИЧЕСКИЙ АСПЕКТ

Статья посвящена изучению средств и способов выражения аксиологического аспекта метафорической репрезентации британской монархии в английских текстах статей, опубликованных на официальных сайтах различных печатных изданий. Анализ показал, что концептуальная метафора репрезентируется в текстах как эксплицитно, так и имплицитно. Особое внимание обращается на амбивалентность оценки британской монархии. В результате декодирования метафоры читатель формирует оценочные установки; экспрессивность метафоры придает высказыванию выразительность, обеспечивает достижение прагматического эффекта.

Адрес статьи: www.gramota.net/materials/2/2019/9/53.html

\section{Источник}

Филологические науки. Вопросы теории и практики

Тамбов: Грамота, 2019. Том 12. Выпуск 9. С. 262-266. ISSN 1997-2911.

Адрес журнала: www.gramota.net/editions/2.html

Содержание данного номера журнала: www.gramota.net/materials/2/2019/9/

\section{() Издательство "Грамота"}

Информация о возможности публикации статей в журнале размещена на Интернет сайте издательства: www.gramota.net Вопросы, связанные с публикациями научных материалов, редакция просит направлять на адрес: phil@gramota.net 
Статья посвящена изучению средств и способов выражения аксиологического аспекта метафорической репрезентации британской монархии в английских текстах статей, опубликованных на официальных сайтах различных печатных изданий. Анализ показал, что кониептуальная метафора репрезентируется в текстах как эксплицитно, так и имплициттно. Особое внимание обращуается на амбивалентность оценки британской монархии. В результате декодирования метафоры читатель формирует оценочные установки; экспрессивность метафоры придает высказыванию выразительность, обеспечивает достижение прагматического эффекта.

Ключевые слова и фразы: метафора; оценка; концептуальная метафора; аксиология; амбивалентность; британская монархия.

\section{Строкан Елена Владимировна}

Российский государственный педагогический университет имени А. И. Гериена, г. Санкт-Петербург strokan@mail.ru

\section{МЕТАФОРИЧЕСКАЯ РЕПРЕЗЕНТАЦИЯ БРИТАНСКОЙ МОНАРХИИ: АКСИОЛОГИЧЕСКИЙ АСПЕКТ}

Метафора и оценка тесно взаимосвязаны, поскольку метафоризация как когнитивный процесс является элементом оценочной деятельности. Несмотря на пристальное внимание ученых к этим двум феноменам языка, проблема специфики аксиологического аспекта метафоры еще не решена, хотя связь метафоры и оценки рассматривается в работах ученых, в частности, Н. Д. Арутюновой, Е. Н. Баниной, Н. В. Аксеновой и др. Таким образом, актуальность данного исследования обусловлена, с одной стороны, недостаточной изученностью аксиологического аспекта метафоры, а с другой - существенной ролью оценочности в семантике метафоры. Научная новизна работы заключается в том, что в ней осуществляется комплексный анализ процесса взаимодействия этих категорий в статьях англоязычной прессы о британской монархии. Цель данного исследования состоит в изучении языковых средств и способов выражения аксиологического аспекта метафорической репрезентации британской монархии. Поставленная цель предопределяет постановку и решение следующих задач: 1) анализ достижений ученых в области аксиологии и теории метафоры; 2) изучение актуализации оценки в метафоре; 3) определение роли контекста в интерпретации оценки. Эмпирическим материалом служат статьи о британской монархии, размещенные на официальных сайтах различных печатных изданий за период с 2011 по 2018 гг.

Метафора как лингвистическая универсалия «охватывает разные аспекты языка и обнаруживается во всех его функциональных разновидностях» [15, с. 11] и является «не только ресурсом образной (поэтической) речи, но и источником новых значений слов» [12, с. 296]; она «лежит в основе многих семантических процессов - развития синонимических средств, появления новых значений и их нюансов, создания полисемии, развития систем терминологии и эмоционально-экспрессивной лексики» [16, с. 9].

На развитие теории метафоры существенное влияние оказала выдвинутая А. А. Ричардсом и разработанная М. Блэком интеракционистская концепция метафоры (an interaction theory of metaphor), или концепция метафоры как взаимодействия [19; 26], в рамках которой метафора рассматривается как «пересечение двух концептуальных систем в целях применения к основному субъекту метафоры свойств и ассоциативных импликаций, связываемых с ее вспомогательным субъектом» [12, с. 297]. Согласно психолингвистической концепции А. А. Ричардса, в метафоре участвуют две мысли о двух разных вещах [26], а в логической концепции М. Блэка - два разнородных референта [19], которые взаимодействуют друг с другом, и в результате синтезируется принципиально новая информация. Такое понимание метафоры получило дальнейшее развитие в теории концептуальной интеграции. Тем не менее ученые, признавая плодотворность интеракции, указывают на слабые стороны этих концепций и считают, что в них «недостаточно учитывается роль собственно человеческого, субъективно-личностного, фактора» [15, с. 33-34], а также не принимается во внимание «ряд свойств метафор, например, аксиологическая ориентация метафоры, антропометричность, роль языковой личности в функционировании метафор (курсив автора статьи. -E. C.)» [5, с. 37].

Традиционно в лингвистике метафора рассматривается как «троп, состоящий в употреблении слов и выражений в переносном смысле на основании сходства, аналогии» [4, с. 223], или определяется как скрытое сравнение [2; 15], «осуществляемое путем применения названия одного предмета к другому и выявляющее таким образом какую-нибудь важную черту второго» [2, с. 64]. Кроме того, метафора описывается как универсальный способ «переосмысления значения слов и перенесения наименования с одного денотата на другой», который «осуществляется на основании сходства (реального или вымышленного) двух объектов» [14, с. 166].

Тем не менее идея скрытого сравнения подвергается критике: например, по мнению Н. Д. Арутюновой, метафора, в отличие от сравнения, лишена синтаксической подвижности, она лаконична и выражает устойчивое подобие, постоянный признак, кроме того, метафора «отбрасывает и основание сравнения» [3, с. 354-355]. «Если в классическом случае сравнение трехчленно (А сходно с В по признаку С), то метафора в норме 
двучленна (А есть В)» [Там же, с. 355]. Более того, поскольку общность характеристик двух объектов не является достаточной для возникновения метафоры, ведь «в метафоре заключена и ложь, и истина, и “нет” и “да”», другими словами, «в метафорическом высказывании можно видеть сокращенное сравнение, но в нем можно видеть и сокращенное противопоставление» [16, с. 18]. Возможно, именно эта «ложь» в метафоре и побуждает адресата к поиску скрытого смысла и тем самым - к выраженной в метафоре оценке.

Рассмотрение метафоры как когнитивного феномена берет свое начало с книги Дж. Лакоффа и М. Джонсона «Метафоры, которыми мы живем». Авторы полагают, что метафора влияет на мышление человека и процесс принятия решений, а также обеспечивает понимание, кроме того, по их мнению, метафора принадлежит не только языку, но и «процессы человеческого мышления во многом метафоричны», т.е. концептуальная система человека структурирована и определена с помощью метафоры, при этом «суть метафоры - это понимание и переживание сущности (thing) одного вида в терминах сущности другого вида» [11, с. 27]. Ученые выделили несколько видов метафоры: 1) структурные, структурирующие один концепт в терминах другого (TIME IS MONEY) (ВРЕМЯ - ЭТО ДЕНЬГИ); 2) ориентационные, организующие целую систему концептов относительно другой системы, многие из них связаны с ориентацией в пространстве (HAPPY IS UP; SAD IS DOWN) (СЧАСТЬЕ СООТВЕТСТВУЕТ ВЕРХУ; ПЕЧАЛЬ - НИЗУ); 3) онтологические, воспринимающие события, деятельности, эмоции, идеи и т.п. как материальные сущности и вещества (THE MIND IS A BRITTLE ОВЈЕСТ) (ДУША - ЭТО ХРУПКИЙ ОБЪЕКТ) [11].

Метафора изучается как ментальный процесс в работах отечественных ученых $[6 ; 7 ; 10 ; 17 ; 18]$ и зарубежных исследователей [21-23; 29].

В данной работе метафора рассматривается не как стилистический прием (троп), создающий образность, а как когнитивный феномен, как средство познания мира, как когнитивная операция, способ познания, категоризации, концептуализации, оценки и объяснения мира, описания одной понятийной сферы в терминах другой понятийной сферы. Метафора может быть представлена логической схемой А is $\mathrm{B}$, такая запись включает наименование обоих метафорических концептов.

Важно отметить, связь метафоры и оценки рассматривалась многими исследователями [1; 5; 9]. Например, Э. В. Будаев определяет метафору как «(основную) ментальную операцию, как способ познания, категоризации, концептуализации, оценки и объяснения мира», уточняя, что взял в скобки слово «основную», т.к. «не все исследователи когнитивной метафоры придают ей статус именно основной операции» [8, с. 20].

Для рассмотрения аксиологического аспекта метафоры необходимо определить оценку как лингвистическую категорию. Оценка предполагает «схематизацию опыта в соответствии с коллективной и индивидуальной шкалой оценок, системами норм, идеалов, стереотипов, ценностей, принятых в рамках той или иной культуры, т.е. оценочную концептуализацию и оценочную категоризацию объектов и событий» [6, с. 13], которые и составляют лингвистический аспект категории оценки. Необходимо отметить, что оценка обладает широким спектром средств выражения, и выбор осуществляется в соответствии с целями автора, его интенцией, т.е. принимается во внимание прагматический аспект оценочного высказывания. Используя метафоры, автор не только выражает индивидуальную оценку тому или иному предмету или явлению, но эта оценка еще экспрессивна и эмоционально окрашена. Кроме того, отмечается лаконичность метафоры [5], т.к. в ней вся «информация “свёртывается”, сжимается, как пружина в заводном механизме, а роль спускового механизма играет экстенсионал метафоры, вызывающий образное представление» [15, с. 14]. Таким образом, можно утверждать, что с точки зрения прагматики, оценка - это часть прагматического значения метафоры, т.к. «метафора выступает как аксиологический механизм речевой деятельности человека» [5, с. 39] и формирует оценочные установки читателя.

Представляется эвристически плодотворным рассмотреть метафорическую репрезентацию британской монархии в аксиологическом аспекте на материале статей, размещенных на официальных сайтах различных печатных изданий.

Британская королевская семья традиционно выступает метонимическим обозначением института монархии в англоязычной прессе за исключением тех статей, в которых обсуждается личная жизнь отдельных членов этой семьи, что позволяет рассматривать в рамках данной статьи номинативные единицы “the Royal Family" (королевская семья) и "the British Monarchy" (британская монархия) как абсолютные синонимы (здесь и далее перевод автора статьи. - E. C.).

В качестве объекта исследования выбрана концептуальная метафора “The Royal Family Is the Firm” («Kopoлевская семья - это фирма»), которая эксплицирована в различных дискурсах. В 2008 году была опубликована книга Пенни Джунор “The Firm: The Troubled Life of the House of Windsor” («Фирма: сложная жизнь дома Виндзоров»), а в 2010 году вышел на экраны фильм “The King's Speech”, в котором король Георг VI произносит фразу: “We're not a family, we're a firm”. / «Мы не семья, мы - фирма»; кроме того, сама королева в узком кругу использует это выражение, а ее супруг, принц Филипп, высказывался об этом публично [Цит. по: 24]. Кроме того, в прессе часто встречаются статьи, в заголовках которых заявляется о том, что королевская семья считается фирмой: “FINANCING THE FIRM: HOW THE ROYAL FAMILY MAKE THEIR MONEY” [24]. / «Финансирование фирмы: как королевская семья зарабатывает деньги»; “Royals to royalties: The Firm is in business” [28]. / «Кopoлевские отчисления королевской семье: Фирма готова к работе»; “Joining The Firm: Can ambitious Meghan cope with a most unmodern court?” [27]. / «Вхождение в состав фирмы: сможет ли амбициозная Меган ужиться с самым несовременным двором?» (здесь и далее сохранены орфография и пунктуация авторов статей. $-E$. $C$.). 
Концептуальная метафора “Тhe Royal Family Is the Firm” является структурной, согласно классификации Дж. Лакоффа и М. Джонсона, поскольку соответствует схеме A is В и наглядно показывает, как для описания одной понятийной сферы применяются термины другой, а именно для описания королевской семьи используется термин из экономической сферы. Благодаря использованию экономического термина, авторы создают ментальный конструкт, который оказывается связанным с предпринимательской деятельностью, а в текстах он детализируется с помощью других терминов, описывающих операционную деятельности предприятия, т.е. доходов и расходов: benefits, profit, revenue, cost и др. [28]. Важно отметить, что понять, какую именно оценку пытаются выразить авторы, можно, только рассматривая каждый конкретный пример употребления метафоры.

Согласно словарным дефинициям, слово firm оценочно нейтрально: “a business concern, especially one involving a partnership of two or more people” [25] («торгово-промышленное предприятие, для которого особенно характерно партнерство двух или более людей»); “a business or company, especially a small one” [20] («предприятие или компания, обычно небольшого размера»), т.е. в определениях отсутствует положительная или отрицательная оценка.

Актуализация концептуальной метафоры “The Royal Family Is the Firm” осуществляется с помощью иных метафор, которые позволяют представить детализированное описание ментального конструкта:

“...the British royal family in these days a very businesslike operation... a media-conscious and relatively transparent enterprise that might be described in business terminology as a real estate and leisure conglomerate with a heritage brand and a highly developed sense of corporate social responsibility" [24]. / «В последнее время королевская семья - деловая компания... крупное предприятие, отличающееся открытостью и представленностью в СМИ, которое может быть охарактеризовано в экономических терминах как многопрофильная корпорация, которая занимается недвижимостью и туризмом, активно поддерживает ответственность бизнеса перед обществом, а также владеет торговой маркой, представляющей культурно-историческую ценность».

В данном примере британская монархия рассматривается автором как крупное предприятие (enterprise) и как многопрофильная корпорация (conglomerate), которая имеет свои социальные обязательства перед народом и государством. Продуктом деятельности этого бизнеса является культурно-исторический бренд "The British Royal Family". Автор статьи выражает положительную оценку деятельности названного предприятия, что следует из замечания о социальных обязательствах. В выражении "highly developed sense of corporate social responsibility” оценка выражается имплицитно, поскольку в обществе существует стереотипное представление, что социальная ответственность (social responsibility) является положительной характеристикой предприятий, при этом оценка усилена с помощью словосочетания highly developed. Создавая единый образ с помощью различных лексических средств, воздействие на читателя усиливается, и в данном случае создается положительный образ британской монархии.

Положительная или отрицательная оценка зависит от точки зрения индивидуума на явление или предмет, в данном случае - на британскую монархию:

"As an institution, the monarchy is a pillar of British life that is admired the world over - but it is also a cost centre, which anti-monarchists see as absorbing state funds that might otherwise go to healthcare or schools. Though that cost is a drop in the bucket of overall public-sector budgets - $\$ 35.7 \mathrm{~m}$ for 2013/14 or just 56 pence per head of population, less than the cost of a first-class postage stamp - today's taxpayer-citizens expect value, performance and good governance, wherever their money goes” [Ibidem]. / «Как институт власти, монархия является не только оплотом британской жизни, вызывающим восхищение во всем мире, но и центром затрат, поглощающим, по мнению анти-монархистов, государственные средства, которые вместо этого могли бы быть направлены на поддержку медицины или образования. Хотя эти затраты - капля в море по сравнению с общим государственным бюджетом - 35,7 миллионов фунтов стерлингов за 2013-2014 гг., или всего лишь 56 пенсов на душу населения, - меньше, чем стоимость почтовой марки, а взамен сегодняшние налогоплательщики ожидают достойный доход, высокую производительность труда и эффективное государственное управление, и неважно, на что тратятся их деньги».

Так, в этом примере можно наблюдать противоположную оценку - если во всем мире британской монархией восхищаются (that is admired the world over) и считают ее оплотом британской жизни (a pillar of British life), т.е. выражают положительную узуальную оценку, содержащуюся в денотативном значении, то для анти-монархистов налоговые отчисления на содержание королевской семьи являются просто статьей расходов, хотя государственные средства можно было бы потратить на образование и медицину, соответственно, в данном случае отрицательная оценка выражается имплицитно. Автор статьи оценивает монархию положительно, т.к. считает, что все эти затраты - капля в море (a drop in the bucket). Он не ограничивается использованием эмоционально окрашенного фразеологизма, но, в соответствии с фреймом концептуальной метафоры, приводит результаты экономических расчетов (затраты каждого жителя королевства не превышают стоимость почтовой марки), тем более, что взамен подданные получают надежную фирму с хорошей репутацией, которая проверена временем и надлежащим образом исполняет свои обязанности, и в таком случае неважно, на что именно уходят деньги налогоплательщиков.

В рассмотренном примере выражается положительная оценка как эксплицитно, благодаря использованию прилагательного good (хороший) и существительного value (польза), которые содержат положительную оценку в денотативном значении, так и имплицитно, в частности метафорой a drop in the bucket (капля в море). Соответственно, можно утверждать, что оценка может менять свою полярность не только в пределах целого текста, но и в пределах одного предложения, в зависимости от указанной точки зрения. 
Положительная оценка британской монархии связана обычно с главой фирмы, т.е. королевой Елизаветой II, но даже в этом случае оценка амбивалентна. С одной стороны, говорится о том, что королева твердо стоит у руля корабля в течение 65 лет (“The current queen, now 92, has sailed a steady ship for 65 years” [27]), при этом для усиления воздействия на читателя используется экспрессивная метафора sailed a steady ship (твердо стоять у руля), которая выражает положительную оценку особенно благодаря прилагательному steady, содержащему положительную оценочность в денотативном значении слова, при этом экспрессивность увеличивается аллитерацией. С другой стороны, в том же абзаце говорится о том, что монарх не так важен, как правящие круги:

"The royal family, or The Firm as it's known to insiders, is run much like a country, by a coterie of civil servants, or courtiers. The monarch is not as important as the continuation of the establishment" [Ibidem]. / «Kopoлевская семья, или фирма, как известно особо приближенным, управляется подобно стране избранным кругом государственных служащих, или придворными. Монарх уже не так важен, как сохранение существования правящих кругов».

Отрицательная оценка выражена эксплицитно, поскольку имя прилагательное important используется в отрицательной грамматической конструкции. Кроме того, на протяжении всей статьи автор выказывает негативное отношение к монархии, считая ее пережитком старины, употребляя словосочетание $a$ most unmodern court (самый несовременный двор) в названии статьи и слово anachronism (пережиток старины) для описания британской монархии. Отрицательная оценка в указанных примерах содержится в денотативном значении прилагательного unmodern (несовременный) и существительного anachronism (пережиток старины). Поэтому можно утверждать, что в данной статье британская монархия предстает перед читателями как старомодная и отсталая, и метафора “The Firm” имеет больше негативную окраску, чем положительную.

Однако в той же статье выказывается и положительное отношение к британской монархии, что свидетельствует об амбивалентности индивидуальной оценки.

Еще один пример актуализации концептуальной метафоры “The Royal Family Is the Firm” также показывает амбивалентность оценки, но в данном случае кажется, что скорее это диалектическое единство, т.к. выражается отрицательная оценка, однако замечается, что невозможно получить что-то хорошее и при этом избежать плохого:

"Perhaps we should not be surprised by moves to build an element of performance-related pay into the Civil List - the income the monarchy is paid by the taxpayer to fund its official duties. It is surely nothing more than good business practice” [28]. / «Возможно, мы не должны удивляться предпринимаемым шагам на пути к получению дохода за оказанные услуги, т.е. получению средств налогоплательщиков, которые финансируют монархию, тем самым давая возможность исполнять королевские обязанности. Это, безусловно, не что иное, как надлежащая практика ведения бизнеса».

Согласно представлениям о действующем предприятии, оно получает доход за оказанные услуги “регformance-related pay" и многое другое, например, развитие туризма, и нет ничего удивительного в том, чтобы оплачивать их за счет налоговых отчислений, и этот очевидный факт рассматривается автором статьи как норма, т.е. как добросовестное ведение дел. Соответственно, отрицательная оценка выражается автором имплицитно, указанием на то, что королевская семья содержится за счет средств налогоплательщиков, а положительная - эксплицитно, прилагательным good в словосочетании “good business practice”. Как уже было отмечено выше, все высказывание выражает амбивалентность и диалектическое единство оценки, а кроме того, оценка может считаться нейтральной, т.к. соответствует норме в представлении автора.

Таким образом, на основе анализа достижений в области метафоры и аксиологии было установлено, что метафора как когнитивная операция формирует оценочные установки читателя и благодаря своей экспрессивности придает высказыванию большую выразительность, тем самым усиливая воздействие на адресата и создавая более значительный прагматический эффект. Анализ эмпирического материала показал, что концептуальная метафора “The Royal Family Is the Firm” в статьях о британской монархии широко распространена. Было доказано, что благодаря использованию экономического термина авторы создают ментальный конструкт, который связан с предпринимательской деятельностью, который в текстах детализируется с помощью других терминов, связанных с операционной деятельности предприятия. Актуализация оценки в рассматриваемой концептуальной метафоре осуществляется с помощью различных лексических средств, используются не только слова, содержащие узуальную оценку в денотативном значении, но также эмоционально окрашенные фразеологизмы и другие экспрессивные метафоры, при этом для усиления воздействия на читателя применяется аллитерация. В ходе исследования было установлено, что положительная или отрицательная оценка репрезентируется в тексте разными способами, не только эксплицитно, но и имплицитно, благодаря лингвистическому и экстралингвистическому контекстам можно судить о том, какая именно оценка выражается. Также в текстах прослеживается амбивалентность оценки, а полярность оценки зависит от точки зрения субъекта оценки, кроме того, рассмотрены примеры нейтральной оценки, соответствующей норме.

Список источников

1. Аксенова Н. В. Оценочные смыслы в метафоре (на материале англоязычной литературы XX века): дисс. ... к. филол. н. СПб., 2007. 173 с.

2. Арнольд И. В. Стилистика современного английского языка. М.: Флинта; Наука, 2002. 384 с. 
3. Арутюнова Н. Д. Язык и мир человека. Изд-е 2-е, испр. М.: Языки русской культуры, 1999. XV+896 с.

4. Ахманова О. С. Словарь лингвистических терминов. Изд-е 3-е. М.: КомКнига, 2005. 576 с.

5. Банина Е. Н. Оценочный компонент значения в семантике метафоры: на материале современного английского языка: дисс. ... к. филол. н. Киров, 2001. 159 с.

6. Болдырев Н. Н. Когнитивные схемы языковой интерпретации // Вопросы когнитивной лингвистики. 2016. № 4. С. 10-20.

7. Бородулина Н. Ю., Звягина А. И. Метафора в аспекте проблемы интердискурсивности // Вестник Московского государственного областного университета. Серия «Лингвистика». 2010. № 2. С. 13-16.

8. Будаев Э. В. Становление когнитивной метафоры // Лингвокультурология: сборник статей. Екатеринбург: Уральский государственный педагогический университет, 2007. Вып. 1. С. 16-32.

9. Иванкова И. В., Макарова О. С. Метафора как средство выражения имплицитной оценки в языке философии // Филологические науки. Вопросы теории и практики. 2016. № 6 (60). Ч. 3. С. 93-95.

10. Краткий словарь когнитивных терминов / сост. Е. С. Кубрякова, В. З. Демьянков, Ю. Г. Панкрац, Л. Г. Лузина. М.: Филол. ф-т МГУ им. М. В. Ломоносова, 1997. 245 с.

11. Лакофф Дж., Джонсон М. Метафоры, которыми мы живем / пер. с англ.; под ред. и с предисл. А. Н. Баранова. М.: Едиториал УРСС, 2004. 256 с.

12. Лингвистический энциклопедический словарь / гл. ред. В. Н. Ярцева. Изд-е 2-е, доп. М.: Большая Российская энциклопедия, 2002. $709 \mathrm{c}$.

13. Метафора в языке и тексте / отв. ред. В. Н. Телия. М.: Наука, 1988. 176 с.

14. Мороховский А. Н., Воробьёва О. П., Лихошерст Н. И., Тимошенко 3. В. Стилистика английского языка. К.: Вища школа, 1984. $241 \mathrm{c.}$

15. Телия В. Н. Коннотативный аспект семантики номинативных единиц. М.: Наука, 1986. 143 с.

16. Теория метафоры: сборник / пер. с англ., фр., нем., исп., польск. яз.; вступ. ст. и сост. Н. Д. Арутюновой; общ. ред. Н. Д. Арутюновой и М. А. Журинской. М.: Прогресс, 1990. 512 с.

17. Чеханова И. В. О когнитивной природе формирования зоометафоры // Международный конгресс по когнитивной лингвистике: сб. мат-лов. Тамбов: Издательский дом ТГУ им. Г. Р. Державина, 2008. С. 472-474.

18. Чудинов А. П. Россия в метафорическом зеркале: когнитивное исследование политической метафоры (1991-2000). Екатеринбург: УрГПУ, 2001. 238 с.

19. Black M. Models and metaphors: Studies in language and philosophy. Ithaca, N. Y.: Cornell University Press, 1962. 276 p.

20. Longman Dictionary of Contemporary English Online [Электронный ресурc]. URL: https://www.ldoceonline.com/ (дата обращения: 16.04.2019).

21. Madsen M. W. Cognitive metaphor theory and the metaphysics of immediacy // Cognitive Science. 2016. № 40 (4). P. $881-908$.

22. McElhanon K. A. From simple metaphors to conceptual blending: The mapping of analogical concepts and the praxis of translation // Journal of Translation. 2006. Vol. 2. № 1. P. 31-81.

23. Núñez R. Conceptual Metaphor, Human Cognition, and the Nature of Mathematics // The Cambridge Handbook of Metaphor and Thought / ed. by Raymond W. Gibbs, Jr. Cambridge: Cambridge University Press, 2008. P. 339-362.

24. O'Gara E. Financing the Firm: How the royal family make their money [Электронный pecypc] // Newsweek. URL: https://www.newsweek.com/queen-special-issuethe-royal-familyqueen-elizabeth-iibritish-businessthe-queen-603709 (дата обращения: 18.04.2019).

25. Oxford English Dictionary ‘Lexico’ [Электронный pecypc]. URL: https://www.lexico.com/en/ (дата обращения: 16.04.2019).

26. Richards I. A. The philosophy of rhetoric. L. - N. Y.: Oxford University Press, 1965. 150 p.

27. Ryan S. Joining The Firm: Can ambitious Meghan cope with a most unmodern court? [Электронный pecypc] // The Independent. URL: https://www.independent.ie/style/celebrity/joining-the-firm-can-ambitious-meghan-cope-with-a-most-unmoderncourt-36918665.html (дата обращения: 14.04.2019).

28. Shrimsley R. Royals to royalties: The Firm is in business [Электронный pecypc] // The Financial Times. URL: https://www.ft. com/content/e31c28ac-a341-11e0-8d6d-00144feabdc0 (дата обращения: 16.04.2019).

29. Steen G. J. Identifying Metaphor in Language: A Cognitive Approach // Style. 2002. Vol. 36. № 3. P. 386-406.

\title{
METAPHORICAL REPRESENTATION OF THE BRITISH MONARCHY: AXIOLOGICAL ASPECT
}

\author{
Strokan Elena Vladimirovna \\ Herzen State Pedagogical University of Russia, St. Petersburg \\ strokan@mail.ru
}

The author examines the ways and means to express the axiological aspect of metaphorical representation of the British monarchy in the English articles posted on the official sites of printed editions. The analysis has shown that the conceptual metaphor is represented both explicitly and implicitly. Special attention is paid to ambivalent assessment of the British monarchy. Decoding the metaphor, a reader forms evaluative attitudes; expressivity of the metaphor imparts expressiveness to a statement, secures pragmatic effect.

Key words and phrases: metaphor; assessment; conceptual metaphor; axiology; ambivalence; British monarchy. 